\title{
Explosive development of winter storm Xynthia over the subtropical North Atlantic Ocean
}

\author{
M. L. R. Liberato ${ }^{1,2}$, J. G. Pinto ${ }^{3,4}$, R. M. Trigo ${ }^{2,5}$, P. Ludwig ${ }^{3}$, P. Ordóñez ${ }^{1}$, D. Yuen ${ }^{3}$, and I. F. Trigo ${ }^{2,6}$ \\ ${ }^{1}$ Escola de Ciências e Tecnologia, Universidade de Trás-os-Montes e Alto Douro (UTAD), Vila Real, Portugal \\ ${ }^{2}$ Instituto Dom Luiz (IDL), Universidade de Lisboa, Lisboa, Portugal \\ ${ }^{3}$ Institute for Geophysics and Meteorology, University of Cologne, Cologne, Germany \\ ${ }^{4}$ Department of Meteorology, University of Reading, Reading, UK \\ ${ }^{5}$ Departamento de Engenharias, Universidade Lusófona, Lisboa, Portugal \\ ${ }^{6}$ Instituto Português do Mar e da Atmosfera (IPMA), Lisboa, Portugal
}

Correspondence to: M. L. R. Liberato (mlr@utad.pt)

Received: 12 February 2013 - Published in Nat. Hazards Earth Syst. Sci. Discuss.: 19 March 2013

Revised: 19 July 2013 - Accepted: 29 July 2013 - Published: 12 September 2013

\begin{abstract}
In winter of 2009-2010 south-western Europe was hit by several destructive windstorms. The most important was Xynthia (26-28 February 2010), which caused 64 reported casualties and was classified as the 2 nd most expensive natural hazard event for 2010 in terms of economic losses. In this work we assess the synoptic evolution, dynamical characteristics and the main impacts of storm Xynthia, whose genesis, development and path were very uncommon. Wind speed gusts observed at more than 500 stations across Europe are evaluated as well as the wind gust field obtained with a regional climate model simulation for the entire North Atlantic and European area. Storm Xynthia was first identified on 25 February around $30^{\circ} \mathrm{N}, 50^{\circ} \mathrm{W}$ over the subtropical North Atlantic Ocean. Its genesis occurred on a region characterized by warm and moist air under the influence of a strong upper level wave embedded in the westerlies. Xynthia followed an unusual SW-NE path towards Iberia, France and central Europe. The role of moist air masses on the explosive development of Xynthia is analysed by considering the evaporative sources. A lagrangian model is used to identify the moisture sources, sinks and moisture transport associated with the cyclone during its development phase. The main supply of moisture is located over an elongated region of the subtropical North Atlantic Ocean with anomalously high SST, confirming that the explosive development of storm Xynthia had a significant contribution from the subtropics.
\end{abstract}

\section{Introduction}

Intense extratropical cyclones are often associated with extreme weather conditions, in terms of wind and precipitation, being among the most severe natural hazards affecting Europe (e.g. Lamb, 1991; Fink et al., 2009; Liberato et al., 2011). During the recent winter of 2009-2010 south-western Europe was hit by destructive storms, including two deadly events only one week apart. The Island of Madeira (Portugal) was hit on 20 February 2010 by severe rainfall, which led to flash-floods and hundreds of landslides, which eventually killed more than 40 people (Fragoso et al., 2012). In this work, we analyse the main impacts, the synoptic evolution and dynamical characteristics of the second event. Storm Xynthia $^{1}$ (26-28 February 2010) developed and crossed over the Madeira archipelago following a similar track to the storm that caused such havoc on this Island the week before. Despite the high level of awareness of all European Meteorological services (particularly those more likely to be affected, Portugal, Spain and France) this storm caused a total of 64 reported casualties, a number larger than well-know North Atlantic (NA) storms such as "Lothar" and "Martin" in 1999, "Kyrill" in 2007 and "Klaus" in 2009 (e.g. Fink et al., 2012). The total economic losses were estimated at least EUR 3.6 billion (USD 4.5 billion) and Xynthia was classi-

\footnotetext{
${ }^{1}$ Storm names employed herein are as given by the Freie Universität Berlin and as used by the German Weather Service. Source: http://www.met.fu-berlin.de/adopt-a-vortex/historie/
} 
fied as the 2nd insured loss event in 2010 lead by the Chilean Earthquake (AON Benfield, 2010). These striking numbers give evidence of the significance for the society of such destructive meteorological events over the Euro-Atlantic region.

The role of latent heat release and moisture advection from the subtropics during the development stages of major NA storms on a comparatively southerly path has been addressed in the literature (e.g. storm "Klaus", cf. Knippertz and Wernli, 2010; Liberato et al., 2011; Fink et al., 2012). High values of equivalent potential temperature $\left(\theta_{\mathrm{e}}\right)$ at low levels tend to reduce the static stability across the troposphere and, so to reinforce the interaction between low level cyclone and high level systems, both of them leading to cyclogenesis: the cyclogenesis processes and interactions are more effective than in normal conditions when static stability is low. Thus, high values of $\theta_{\mathrm{e}}$ at $850 \mathrm{hPa}$ in the warm sector of a cyclone are generally interpreted as an indicator for strong latent heat release which may support the intensification of the cyclone (Fink et al., 2009; Pinto et al., 2009; Liberato et al., 2011).

The occurrence of these two disruptive extreme events in February 2010 fits within a wider context of the entire 2009-2010 winter, which was characterised by extremely cold weather conditions over large parts of the Northern Hemisphere, including the USA, Europe and China. This fact has been linked to the record breaking negative values of the North Atlantic Oscillation (NAO) or Arctic Oscillation (AO) indices (Cattiaux et al., 2010; Seager et al., 2010; Wang et al., 2010). In particular, the polar jet latitude over the central and Eastern NA was systematically between 30 and $40^{\circ} \mathrm{N}$, a value corresponding to the lowest end in the distribution during the Reanalysis period (cf. Santos et al., 2013). This also had implications over the Iberian Peninsula, where large sectors of western and southern Iberia were anomalously wet, including historical maximum values in winter precipitation for some stations (cf. Andrade et al., 2011; Vicente-Serrano et al., 2011).

In this paper we present a comprehensive assessment of storm Xynthia, describing its socio-economic impacts over Europe and its lifecycle, with special emphasis on its explosive development. The description of the synoptic-scale development is discussed by means of classical cyclogenetic factors (e.g. Uccellini and Johnson, 1979; Chang et al., 1984; Browning, 1997; Pinto et al., 2009). A simulation with a regional climate model (RCM) is used to enable a more detailed view of the cyclone development and the area affected by the windstorm. Finally, a lagrangian approach is used to identify the moisture sources, sinks and moisture transport associated with the cyclone during its development phase. The implications and conclusions are presented in the final section.

\section{Data and methodology}

\subsection{Meteorological data}

We have used the European Centre for Medium-Range Weather Forecasts (ECMWF) Reanalyses (ERA Interim; Dee et al., 2011) at full temporal (six-hourly) and spatial (T255; interpolated to $0.75^{\circ}$ regular horizontal) resolutions to analyse the large-scale conditions associated with the development of the studied storm. The $\theta_{\mathrm{e}}$ at the $850 \mathrm{hPa}$ pressure level, here used as an indicator of the combined effect of latent and sensible heat, was computed following Bolton (1980).

Maximum gust speeds observed at more than 500 stations located in Europe (Fig. 2) were retrieved from preliminary reports published by the Meteorological services from Portugal, Spain and France as well as from OGIMET website (www.ogimet.com). Weather charts provided by the German Weather Service (DWD, Deutscher Wetterdienst) and EUMETSAT satellite images were used for the surface analysis of synoptic development and cloud patterns.

\subsection{The COSMO model}

The COSMO model (http://www.cosmo-model.org) is used in its Climate Limited area Model (COSMO-CLM version 4.8, hereafter CCLM) to perform a simulation of winter storm Xynthia. The CCLM is a non-hydrostatic regional climate model and has been applied to various needs on several domains and scales (Rockel et al., 2008). Here, the model domain (Fig. 4a) covers large parts of the NA Ocean and Europe featuring a horizontal resolution of $0.22^{\circ} \times 0.22^{\circ}$ (about $25 \mathrm{~km}$ grid size) with 32 layers in the vertical. ERA-Interim data (see above) is used as boundary data to force the model. To keep the simulation towards analysed data, spectral nudging is applied to the horizontal wind components $(U, V)$. The influence of the spectral nudging on the model development is strong at high model levels, but it is weak at $850 \mathrm{hPa}$. Therefore, the influence of this technique within the boundary layer is very limited. The simulation of Xynthia starts at 00:00 UTC on 26 February 2010 and covers a period of $96 \mathrm{~h}$ (4 days).

\subsection{Lagrangian approach to identify the moisture source region to the cyclone}

The Lagrangian analysis of the transport of moisture was performed with the FLEXPART model (Stohl et al., 1998; Stohl and James, 2004, 2005). As part of the initialisation of the model, the atmosphere is split homogeneously in a large number of parcels, the so-called "particles", each representing a small fraction of the total atmospheric mass. Particles are allowed to move freely (forwards or backwards in time) with the observed wind maintaining their mass constant. FLEXPART uses reanalysis data to calculate the gridscale advection. In this study FLEXPART simulations were 
performed using one degree resolution and 60 model vertical levels available in ERA Interim (see above) at 00, 06, 12, 18:00 UTC and forecast input for the intermediate time steps $(03,09,15,21)$, covering the large-scale window that encloses NA and Europe $\left(140^{\circ} \mathrm{W}-50^{\circ} \mathrm{E}, 0-60^{\circ} \mathrm{N}\right)$ to the top of the atmosphere at $0.1 \mathrm{hPa}$. At any given time step, the average number of particles tracked over this domain is about 1.5 million.

Values of the specific humidity, $q$, are interpolated to the particle positions from the ECMWF analysis grid. The information of the trajectories allows the computation of moisture variations $(e-p)$ by means of specific humidity changes in time $(\mathrm{d} q / \mathrm{d} t)$ and

$e-p=m \frac{\mathrm{d} q}{\mathrm{~d} t}$,

where $e$ and $p$ are respectively the rates of moisture increase and decrease of the particle along its trajectory and $m$ represents its mass. By adding $(e-p)$ for all the particles in the atmospheric column over a given area $A$ it is possible to compute $(E-P)$, the surface freshwater flux, where $E$ is the evaporation and $P$ the precipitation rate per unit of area:

$(E-P) \approx \frac{\sum_{k=1}^{K}(e-p)_{k}}{A}$.

In Eq. (2) $K$ is the number of particles residing over the area $A$. By integrating all the changes of all the particles aimed towards $A$, it is possible to find the areas where those particles have either gained $(E-P>0)$ or lost $(E-P<0)$ moisture along their path towards the selected area.

Following Liberato et al. (2012), this procedure is here applied to track the sources, the sinks and the transport of moisture associated with a moving cyclone during the explosive development. During this stage, an amplified wedge of warm and moist air, known as the warm sector of the cyclone, forms at the south-eastern side of the cyclone centre. This is a typical feature for Northern Hemisphere extratropical cyclones (e.g. Dacre et al., 2012). A $5^{\circ} \times 5^{\circ}$ longitude/latitude box was chosen to comprise the centre of the cyclone and its south-eastern warm sector, evaluating $(E-P)$ along the back-trajectories of the particles residing in a given time on the total column over the area defined by this moving box. Sensitivity studies on the position and dimensions of this box have been performed, showing that the chosen box and its dimensions are adequate to represent the warm sector of the cyclone (not shown). This allows obtaining an estimate of the net freshwater flux $(E-P)$, over the days for which the integration was performed. The $(E-P)$ back trajectory values for specific days are denoted by $(E-P)^{-n}$ (the negative sign denotes that the analysis is performed backward in time to be consistent with the convention adopted in Stohl et al., 2005). Here, $(E-P)^{-2}$ shows the regions where the particles gained or lost moisture during the two previous days of the trajectory.

\section{Impacts}

The meteorological and socio-economic impacts of storm Xynthia affected a wide region in western Europe, including Portugal, Spain, France, Belgium and Germany. Examples of destruction can be seen in Fig. 1. Windstorm Xynthia struck Portugal and Spain on 27 February and hit the French Atlantic coast on 28 February, continuing its track towards north-east to Belgium, the Netherlands and Germany. Severe storm force gusts of over $40 \mathrm{~m} \mathrm{~s}^{-1}$ were measured at low-level stations, from the Atlantic archipelagos of Madeira and Canary Islands but particularly over Iberia and France (Fig. 2). Strong winds induced waves as high as eight metres along coastal locations in Portugal, Spain (Fig. 1a) and France (Aon Benfield, 2010). According to data available from the Spanish Oceanographic Institute (IEO) a buoy moored 22 miles north of Santander registered a peak of significant wave height over $14.88 \mathrm{~m}$, between 18:00 UTC and 19:00 UTC on the afternoon of 28 February (Fig. 3), when the buoy anchor cable broke and the buoy drifted away.

Wind uprooted numerous trees (Fig. 1b), blew down electricity masts and blew roofs away. In the French Atlantic coast, the storm surge combined with a high tide and large waves caused flood defences to fail along the coast from the mouth of river Gironde, near Bordeaux, up to the Loire Estuary. Over 50000 ha of land were flooded and consequently France registered 47 fatalities (the highest amount of casualties caused by Xynthia). Most of these deaths occurred as a consequence of the flooding along the Atlantic coast, although a small number of people died as a result of storm debris. In some houses in La Faute-sur-Mer (Fig. 1c), the water level rose to a height of $2.5 \mathrm{~m}$ within half an hour following the failure of dikes and subsequent widespread flooding. Reports suggest that around 10000 people were forced to evacuate their homes on the French Atlantic coast (Lumbroso and Vinet, 2011).

Xynthia also caused considerable damage in Belgium, the Netherlands and Germany, where winds were also still sufficiently strong (Fig. 2) to uproot trees and blow off roofs. Nearly two million people lost access to electricity as a direct consequence of the event, with one million power outages in France alone. Intense rain periods associated to Xynthia also triggered flooding in the United Kingdom. The overall number of claims was estimated at more than 100000 with insured losses amounting to nearly EUR 1.5 billion (USD 2 billion) in France alone, with an additional EUR 1.3 billion (USD 1.65 billion) in combined insured losses from Portugal, Spain, Belgium and Germany. Total economic losses were estimated at EUR 3.6 billion (USD 4.5 billion). 

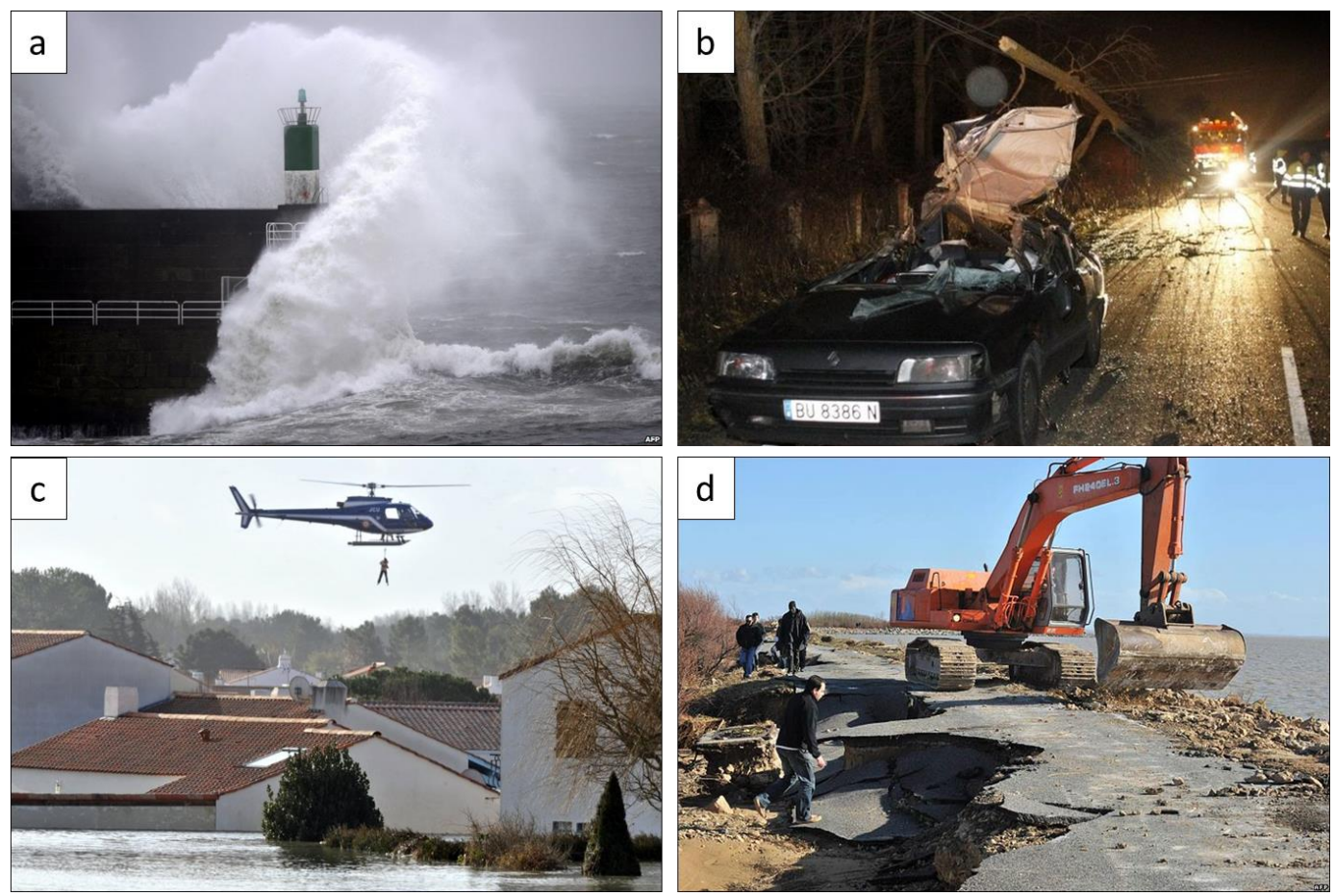

Fig. 1. Photos documenting the impact of storm Xynthia, showing (a) A Guarda, Spain 27 February 2010. (b) Arlanzón, Spain 28 February 2010. (c) La Faute-sur-mer, France 28 February 2010. (d) Aiguillon Sur Mer, France 28 February 2010. The sites are identified respectively with a number on the map of Fig. 2 (pictures 1a, 1c and 1d from AFP and picture 1b from AP, all available from http://news.bbc.co.uk/2/hi/ in_pictures/8541808.stm).

\section{Results}

\subsection{Results from regional modelling}

In this section, a simulation with CCLM is described to enable a detailed view of the cyclone development and of the area affected. Figure 4a shows the tracks of storm Xynthia as represented in ERA-Interim (blue) and the CCLM simulation (green) at 6-hourly intervals. Additionally, the maximum wind gust at each grid point (footprint of the storm) from CCLM is also displayed. Only gusts above $20 \mathrm{~m} \mathrm{~s}^{-1}$ are shown. The tracks, i.e. the trajectories of the storm centre, for ERA-Interim and CCLM are generally in good agreement, although the track of the CCLM simulation is slightly shifted southward before reaching the coast of the Iberian Peninsula, as well as later over the Baltic Sea. As expected, the highest wind gust values occur mainly on the southern flank of the storm path: values above $40 \mathrm{~ms}^{-1}$ are simulated offshore the Portuguese Coast (close to Madeira) and over the Bay of Biscay. Overall, simulated values over Iberia, France and Germany are compatible with the observed pattern (e.g. the much lower values at southern Iberia or lee of Pyrenees, cf. Fig. 2). Likewise, the evolution of the core pressure is rather similar in ERA-Interim and CCLM (Fig. 4b). However, the pressure drops faster for CCLM (green line) during the initial stages being very similar to ERA-Interim (blue line) just before reaching the north-western tip of Iberia. Afterwards, the CCLM core pressure is again lower than ERA-Interim over Bay of Biscay (with a minimum of $967 \mathrm{hPa}$ ) and further downstream. The overall capacity of the CCLM to reproduce the spatial track, core pressure evolution and associated wind gust field confirms the good ability of this model even under such extreme conditions (c.f. Born et al., 2012).

\subsection{Description of the synoptic-scale development of Xynthia}

The synoptic characteristics of Xynthia development are briefly discussed in this section. Figure $5 \mathrm{a}-\mathrm{c}$ display the surface analysis charts as derived by the DWD for three time steps during the phase of rapid intensification of the storm. On 26 February 12:00 UTC, Xynthia appeared as a developing cyclone (Fig. 5a). The cyclone centre, with an analysed core pressure below $995 \mathrm{hPa}$, is located just west of the $30^{\circ} \mathrm{W}$ longitude and further south than usual, over the subtropical NA Ocean. About $18 \mathrm{~h}$ later (27 February 06:00 UTC, Fig. 5b), the cyclone underwent rapid intensification as it moved eastward, close to the Portuguese coast, with the core pressure dropping below $975 \mathrm{hPa}$.

The concept of explosive cyclogenesis was first introduced by Bergeron (1954), referring to rapidly developing storms with a drop in central pressure of at least $24 \mathrm{hPa}$ in $24 \mathrm{~h}$. 


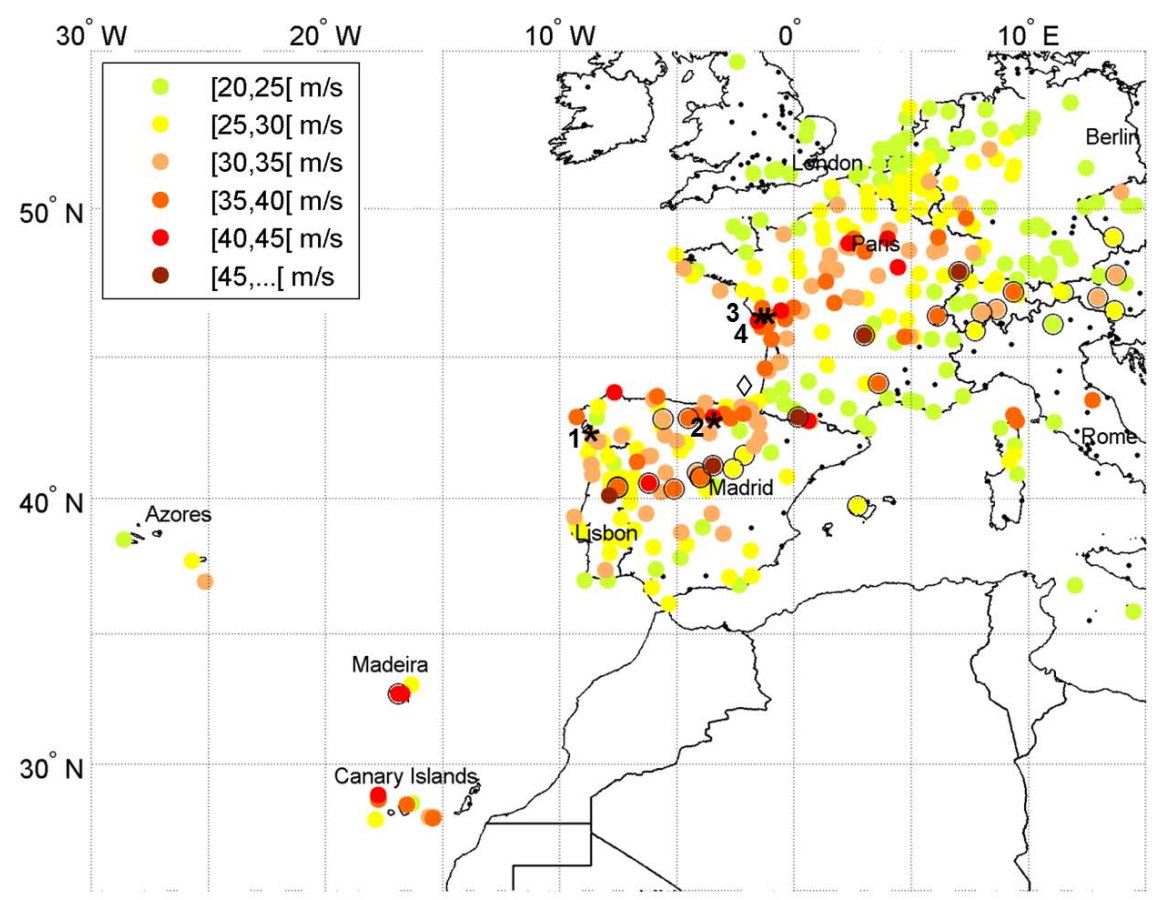

Fig. 2. Maximum wind gusts (in $\mathrm{m} \mathrm{s}^{1}$ ) at synoptic stations reported during the period from 26 February to 1 March 2010. A black dot denotes stations where values below $20 \mathrm{~m} \mathrm{~s}^{-1}$ were recorded. A black circle indicates mountain stations (with an altitude higher than 1000 ma.s.1.). Numbers, from 1 to 4, represent the sites mentioned on Fig. 1 and the approximate location of the IEO buoy is marked with the symbol $\diamond$.

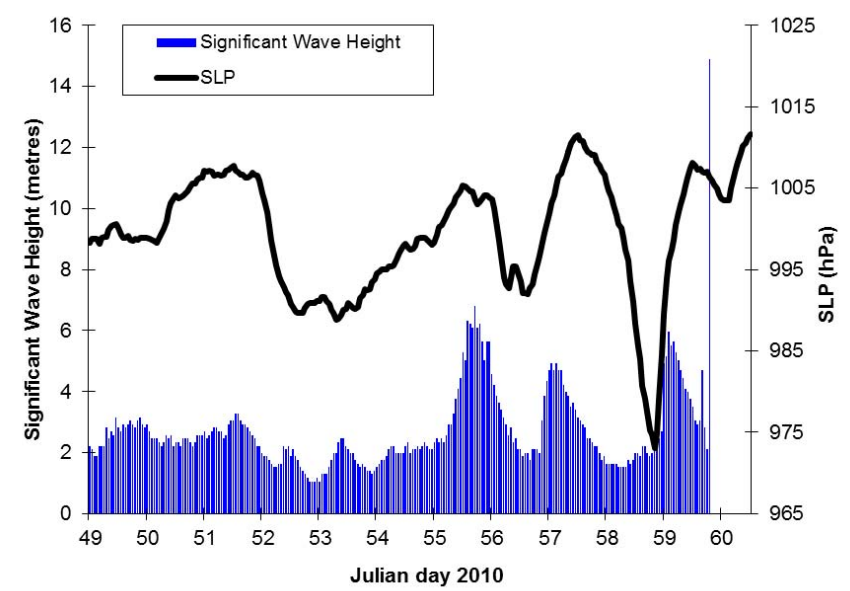

Fig. 3. Hourly averages of significant wave height and sea-level pressure between 18 February and 1 March 2010 from the Spanish Oceanographic Institute (IEO) buoy located 22 miles north of Santander. The approximate location of the buoy is marked with the symbol $\diamond$ on Fig. 2.

Since this critical deepening rate concerned lows developing at high latitudes, typically around $60^{\circ} \mathrm{N}$, the threshold was later generalised by Sanders and Gyakum (1980) to all extratropical cyclones, through the introduction of a geostrophic adjustment factor to any latitude $\varphi\left(\sin 60^{\circ} / \sin \varphi\right)$. Xynthia develops at relatively low latitudes, which is uncommon for this type of phenomena (e.g. Trigo 2006). The pressure drop of about $20 \mathrm{hPa}$ during the first $18 \mathrm{~h}$ of maximum deepening occurs at an average latitude of $37.5^{\circ} \mathrm{N}$, which corresponds to an equivalent rate of $28.5 \mathrm{hPa}$ at $60^{\circ} \mathrm{N}$. The system underwent further intensification during the next hours, being therefore well within the explosive cyclogenesis classification. After this very fast developing stage, the warm sector already covered half of the Iberian Peninsula while the cold front approached the archipelagos of Madeira and Canary Islands. The cyclone centre moved towards the Bay of Biscay, $18 \mathrm{~h}$ later (28 February 00:00 UTC, Fig. 5c), and it is located just off the French Atlantic coast, reaching its absolute minimum core pressure below $970 \mathrm{hPa}$. The corresponding composite satellite image from a geostationary platform is shown in Fig. 5d. The cold front passed over the Iberian Peninsula during the previous couple of hours and was accountable for severe wind gusts and rough seas along the Spanish northern coast (cf. Fig. 3).

The evolution of atmospheric fields for the same three time steps is depicted in Fig. 6. Low level $\theta_{\mathrm{e}}$ at $850 \mathrm{hPa}$ (Fig. 6a, c, e) and upper air jet stream and wind divergence at $300 \mathrm{hPa}$ as well as the geopotential height (gpdm) at $500 \mathrm{hPa}$ (Fig. 6b, $\mathrm{d}, \mathrm{f}$ ) are displayed. The surface cyclone core is indicated in each panel by a black dot. On 26 February 12:00 UTC, the cyclone is located at the tip of a broad area with high val- 

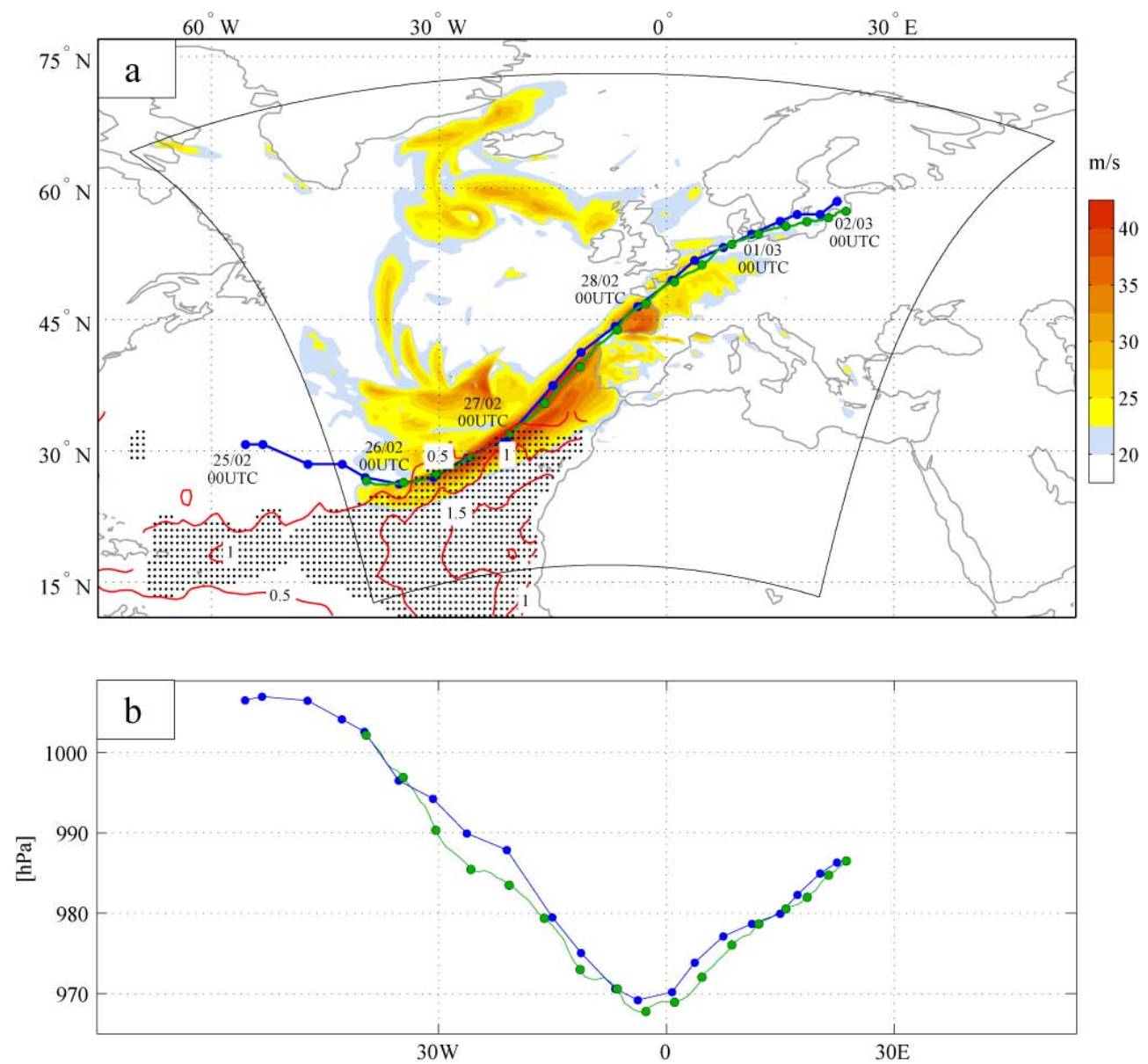

Fig. 4. (a) Surface track of Xynthia as represented in ERA-interim (blue) and in the CCLM simulation (green). Wind gust field corresponds to local maximum wind values $\left(\mathrm{m} \mathrm{s}^{-1}\right)$ during simulation period. The position of the storm at six-hourly intervals is marked with a filled circle. The SST anomaly over the south-eastern North Atlantic for the month February 2010 is depicted as red isolines (each $0.5 \mathrm{~K}$ ). Areas with an SST anomaly exceeding the climatological standard deviation by a factor of 2 are dotted. (b) The corresponding core MSLP data are shown for the period 00:00 UTC 25 February 2010 to 00:00 UTC 2 March 2010.

ues of $\theta_{\mathrm{e}}$ (Fig. 6a). Results by Fink et al. (2012) provide evidence that diabatic processes were quite important at this development stage. At the same time, the cyclone is located vertically aligned to a jet stream with a split structure with two branches (or jet streaks) one extending from the northwestern towards the south-eastern NA and another orientated more zonally from the Azores towards Italy. High values of upper level divergence appear in the vicinity of the cyclone, between the two branches. Furthermore, the surface cyclone is located upstream regarding an approaching upper level trough at $500 \mathrm{hPa}$ (Fig. 6b). About $18 \mathrm{~h}$ later (27 February 06:00 UTC), the cyclone is located just offshore the Portuguese coast (Fig. 6c) and the tongue of warm and moist air still supplies the cyclone with energy from lower levels at that time. The structure of the upper level jet stream, being displaced towards a north-eastern direction, is largely preserved, exhibiting again a split structure and large amounts of upper-air divergence (Fig. 6d). The trough remains al- most stationary, with a small disturbance upstream along the $536 \mathrm{gpdm}$ isoline, just above the surface cyclone. Another $18 \mathrm{~h}$ later (28 February 00:00 UTC) Xynthia reaches the Bay of Biscay and will make landfall at the French Atlantic coast within the next couple of hours (Fig. 6e). At that time, the development of the storm has virtually ceased. The supply of warm and moist air is weakening, as the storm gets truncated from the reservoir of the warm and moist air masses with high $\theta_{\mathrm{e}}$ (Fig. 6e). By that point, the warm sector had shrunk drastically and the cyclone evolves to start its occlusion process soon (cf. Fig. 5c). At the upper levels we may still observe large values of wind divergence at $300 \mathrm{hPa}$, between the two jet streaks (Fig. 6f). As the northern jet streak weakens (down to maximum wind speeds of about $60 \mathrm{~m} \mathrm{~s}^{-1}$ ), the upper level conditions become unfavourable for further development. The trough at $500 \mathrm{hPa}$ moves further to the east, while the surface cyclone is still located upstream within 

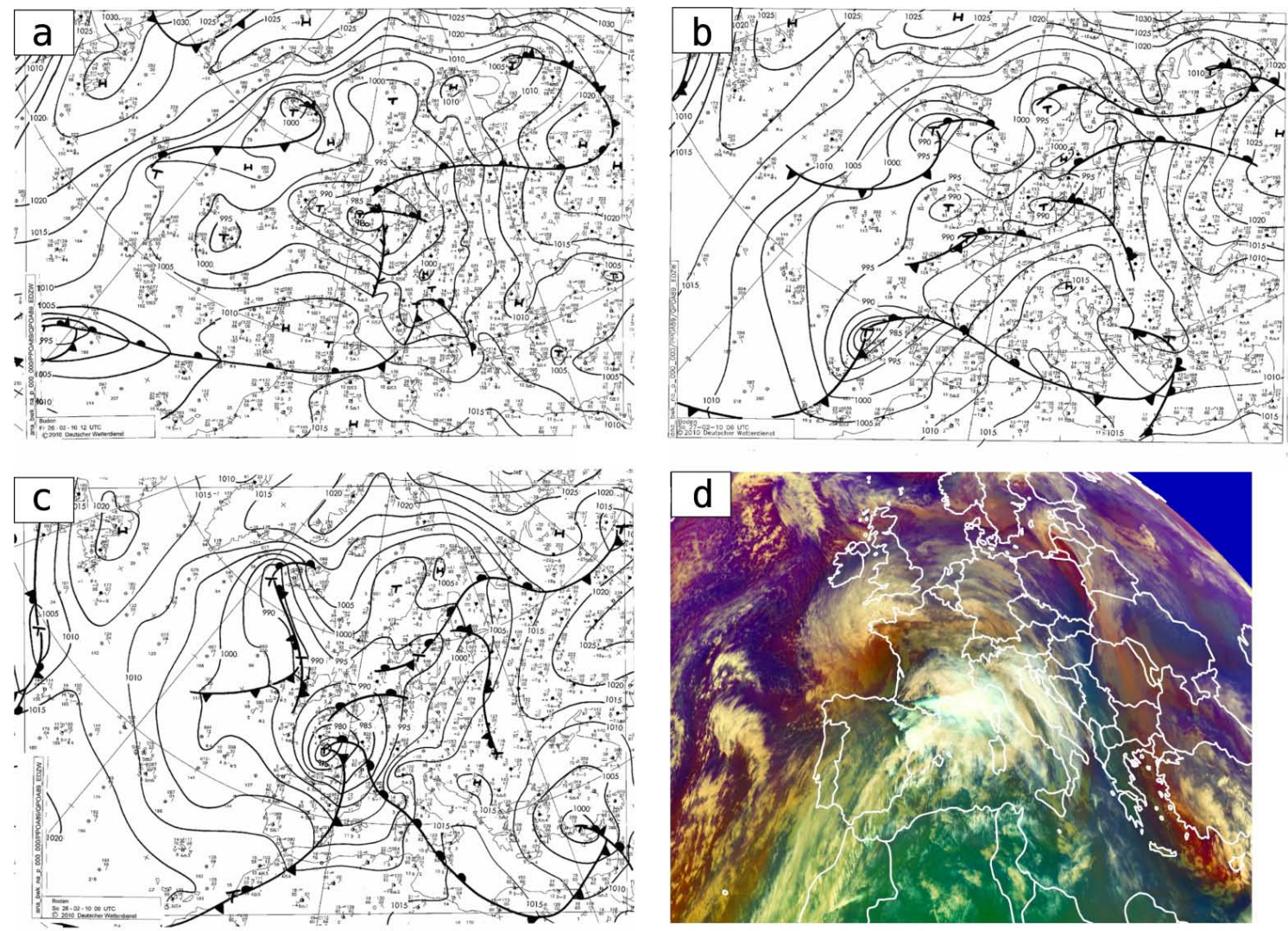

Fig. 5. (a) synoptic analysis in surface for 12:00 UTC 26 February 2010 (b) same for 06:00 UTC 27 February 2010 (c) same for 00:00 UTC 28 February 2010. (d) Composite image (often referred to as "air mass RGB") obtained with the following Meteosat channels for 28 February 2010 close to 00:00 UTC: water vapour $(6.2 \mu \mathrm{m}$ and $7.3 \mu \mathrm{m})$, ozone $(9.7 \mu \mathrm{m})$ and thermal infrared $(10.8 \mu \mathrm{m})$.

a small wave disturbance. The cyclone keeps propagating north-eastward the trough along the 520 gpdm isoline.

Figure 5d shows a composite image, often referred to as "air mass RGB" (http://oiswww.eumetsat.org/IPPS/html/ MSG/RGB/AIRMASS/), obtained with the Meteosat observations for 28 February 2010 close to 00:00 UTC indicated below. This composite makes use of water vapour $(6.2 \mu \mathrm{m}$ and $7.3 \mu \mathrm{m})$, ozone $(9.7 \mu \mathrm{m})$ and one thermal infrared $(10.8 \mu \mathrm{m})$ channels, enhancing differences in temperature, moisture and cloud height: high/mid-level appear white/pinkish, while dry stratospheric air is revealed in reddish colours. The figure shows the cloud structure of the cyclone just before making landfall. A band of clouds stretching from the NA towards the Mediterranean and running parallel to the cold front may be assigned to the warm conveyor belt of the cyclone system. Figure 5d shows increasing cloud top heights from south-west to north-east as would be expected along the rising relatively warm and wet air within the warm conveyor belt. The cold conveyor belt bends back around the cyclone centre at the north-western edge. Encircling the cyclone centre from the southern tip towards the direction of the movement, a region without clouds and appearing in reddish colour indicating dry air/low tropopause in this type of composite image (Fig. 5d), is noticeable over the Bay of Biscay. This may be explained through descending dry air from aloft, being associated with the dry intrusion, which is a common feature during the development of extratropical cyclones (Browning, 1997).

The radiosonde profiles confirm the above mentioned dry intrusion. Figure 7 shows the evolution of radiosonde profiles at 12:00 UTC for Funchal, Madeira for 26 (black) and 27 (blue) February. On 26 February the skew-T log-P diagram shows clearly the existence of a deep layer of warm, saturated moist air mass extending from the surface to around $780-800 \mathrm{hPa}$. A cold, stable dry air mass associated with a dry intrusion may be found on the overlaying layer around 750-700 hPa (black lines). On 27 February 2010 (blue line) the dry slot around $700 \mathrm{hPa}$ was significantly intensified and an inversion at lower levels may be clearly identified.

\section{Moisture sources, sinks and transport}

To identify the origin of the main moisture sources, sinks and moisture transport associated with Xynthia's explosive development, a box of $5^{\circ}$ latitude/longitude was defined southeast of the tracked cyclone position (minimum pressure 

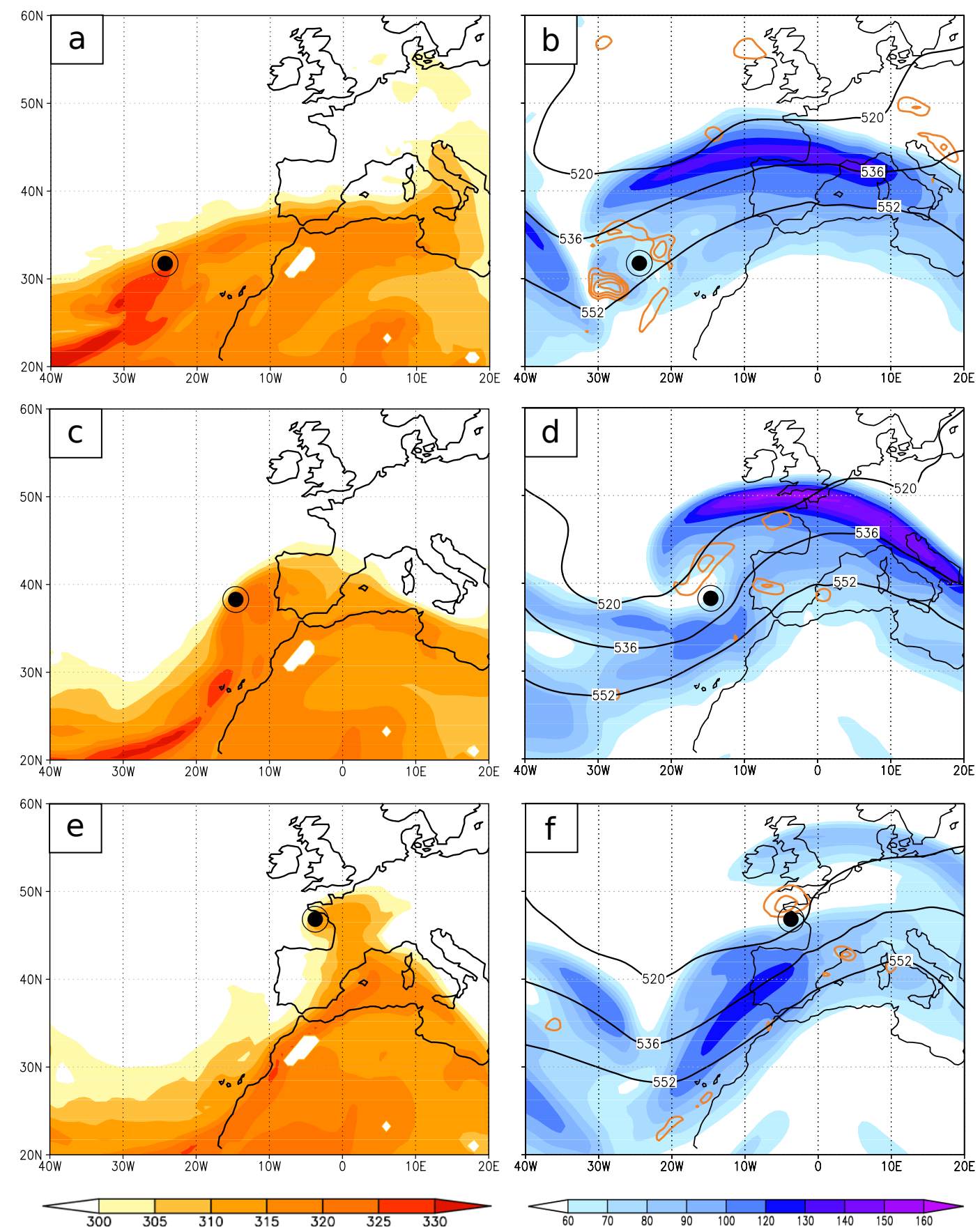

Fig. 6. Large-scale conditions associated with the development of storm Xynthia. (a) $\theta_{\mathrm{e}}(\mathrm{K})$ at $850 \mathrm{hPa}$ for 12:00 UTC 26 February 2010 . (b) Jet (shaded: $\mathrm{m} \mathrm{s}^{-1}$, see colour bar) and upper air divergence (orange contours every $2 \times 10^{-5}\left(\mathrm{~s}^{-1}\right.$ ) above $4 \times 10^{-5}\left(\mathrm{~s}^{-1}\right)$ ) at $300 \mathrm{hPa}$ for 12:00 UTC 26 February 2010. The black contours show the geopotential height (gpdm) at 500 hPa. (c) Same as (a) for 06:00 UTC 27 February 2010. (d) Same as (b) for 06:00 UTC 27 February 2010. (e) the same as (a) for 00:00 UTC 28 February 2010. (f) Same as (b) for 00:00 UTC 28 February 2010. The cyclone position at corresponding time is marked with a circle.

position) for every $6 \mathrm{~h}$ during the period of the explosive phase (represented by a square on each panel from 26 February 06:00 UTC to 28 February 00:00 UTC, Fig. 8). Afterwards the virtual air particles in the overlying air column inside this box were tracked backward. Analysis of the $E-P$ values indicates where and when the moisture was gained or lost. The 2-day integrated $E-P$ fields were computed and are shown in Fig. 8. The analyses of these patterns provide a good representation of source and sink regions of moisture from particles inside the warm sector of Xynthia. 


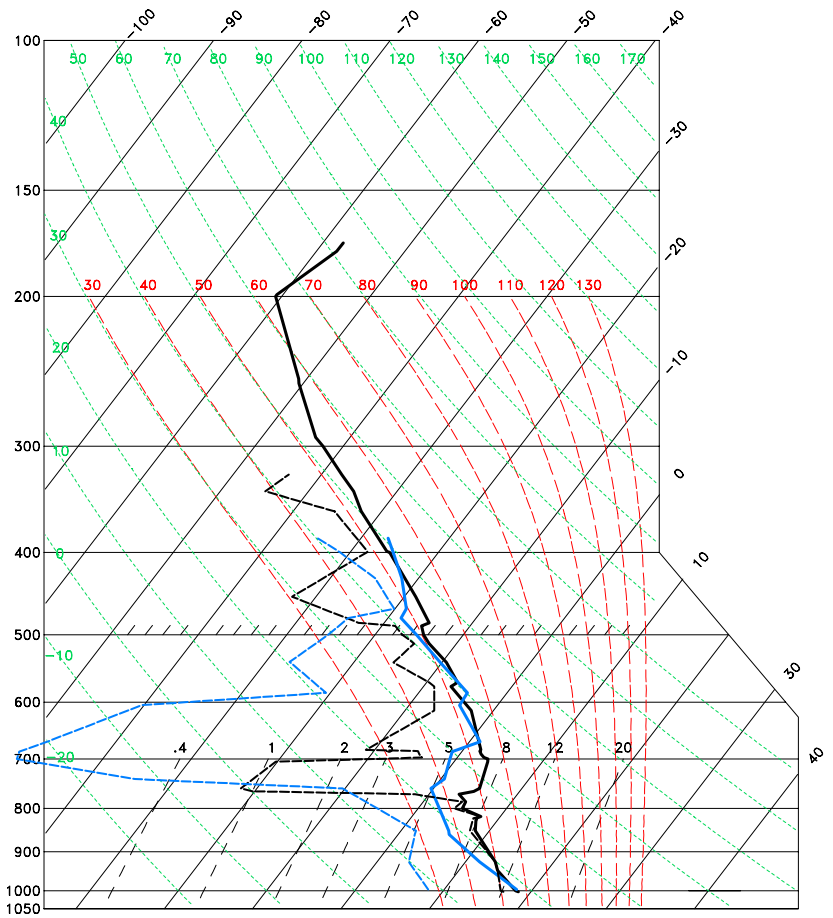

Fig. 7. Projection on a skew-T diagram for the 26 February 2010 (11:09 UTC) sounding at Funchal, Madeira (black symbols) and for the 27 February 2010 (at 11:10 UTC, in blue symbols).

In the regions characterized by positive $E-P$, the excess of evaporation over precipitation indicates a net moisture gain. That is the case during Xynthia's development phase at the equatorward region of the cyclone over the subtropical Atlantic Ocean. The orange areas on $E-P$ maps correspond to the main regions in which the air masses gained moisture during the 2 previous days. Figure 8 a shows that noticeable masses of air over the subtropical Atlantic ocean are characterized by positive $(E-P)^{-2}$, proving that the (sub)tropical oceanic region was the main moisture source during the explosive cyclogenesis. In contrast, the value $(E-P)^{-2}$ is negative for air masses in the surroundings of the cyclone centre. The following panels make evidence for the persistent importance of this source region throughout the entire explosive development phase, since the cyclone continued to be fed by moisture from this region. When analysing these $E-P$ panels we should keep in mind that there is also evaporation on the bluish (negative) regions, as well as precipitation on the orange (positive) regions. Thus while most of the precipitation must have been originated in the moisture source areas detected we acknowledge that a fraction may have its origins in negative $E-P$ regions observed and even through local recycling. Another relevant feature identified from the sequence of panels on Fig. 8 is the fact that this oceanic source region is progressively elongated, showing that the cyclone is being continuously fed both from the original (sub)tropical region and also from nearby moist air, following its track.
It is also interesting to note the intensification of the moisture recharge (orange) region from 00:00 UTC to 06:00 UTC on 27 February, i.e. precisely the period when Xynthia experienced the larger pressure drop (see Fig. 4) over the Atlantic Ocean off the Moroccan coast.

To confirm that a tongue of warm, moist air was capable of supplying the cyclone with energy originated at lower levels up we represent the 2 day backward trajectories of the particles inside the chosen box (Fig. 9), respectively with values of height (left panels), specific humidity (central panels) and temperature (right panels). From these panels it is clear that particles originating over the (sub)tropical moisture source region transport significant amounts of warm moisture (values over $8 \mathrm{~g} \mathrm{~kg}^{-1}$ ) from lower levels (below $1000 \mathrm{~m}$ ) upward (Fig. 9a). A small exception refers to the subset of particles that the cyclone incorporates from the lower levels at midlatitudes (originating from the region near Florida) during 26 February (Fig. 9b). It is also interesting to note that almost all pathways related with mid-latitude air masses are found at higher levels. These trajectories are well organized and correspond to a high density of dry particles transported rapidly by the jet stream. From the following panels it is clear that the explosive development of the cyclone was continuously fed by low level particles (Fig. 9c.1) from the region off the coast of Morocco, with moist, warm air (Fig. 9c.2-3). Furthermore, this intensification is also supported by the inclusion of dry low level air from the north as well as from the intrusion of dry air from higher levels, which is evident on panels for 06:00 UTC 27 February (Fig. 9d). When Xynthia reached the Bay of Biscay the storm got truncated from the oceanic reservoir of the moist air masses and its supply of moist air was reduced (Fig. 9d) which is coincident to the end of the storm's development. A significant fraction of low level particles were then drier (Fig. 9d.2) in agreement with the fact that the warm sector shrunk drastically and the cyclone is to begin its occlusion phase soon (cf. Fig. 5c). The sea surface temperature (SST) monthly anomaly for February 2012 (Fig. 4a) reveals that during this period the (sub-)tropical region of the Atlantic Ocean was 1 to $2{ }^{\circ} \mathrm{C}$ above the long-term climatological mean. This area with enhanced SST corresponds well to the source region of the trajectories that were associated with the development of Xynthia. Please note that the presence of enhanced SST over the subtropical North Atlantic close the African coast is both consistent with the concurrent negative NAO phase and the El Niño occurrence in the previous months (cf. Wanner et al., 2001; Enfield and Mayer, 1997). The reasons for the exceptional magnitude of the SST anomaly in February 2010 are left for future research.

Results presented here make evidence that the moisture transport from (sub)tropical Atlantic Ocean plays a relevant role in the cyclone explosive development. Enhanced $\theta_{\mathrm{e}}$ at $850 \mathrm{hPa}$ may increase de baroclinic processes or temperature/moisture gradients between polar-subtropical air masses, which in turn may reinforce the cyclogenesis 

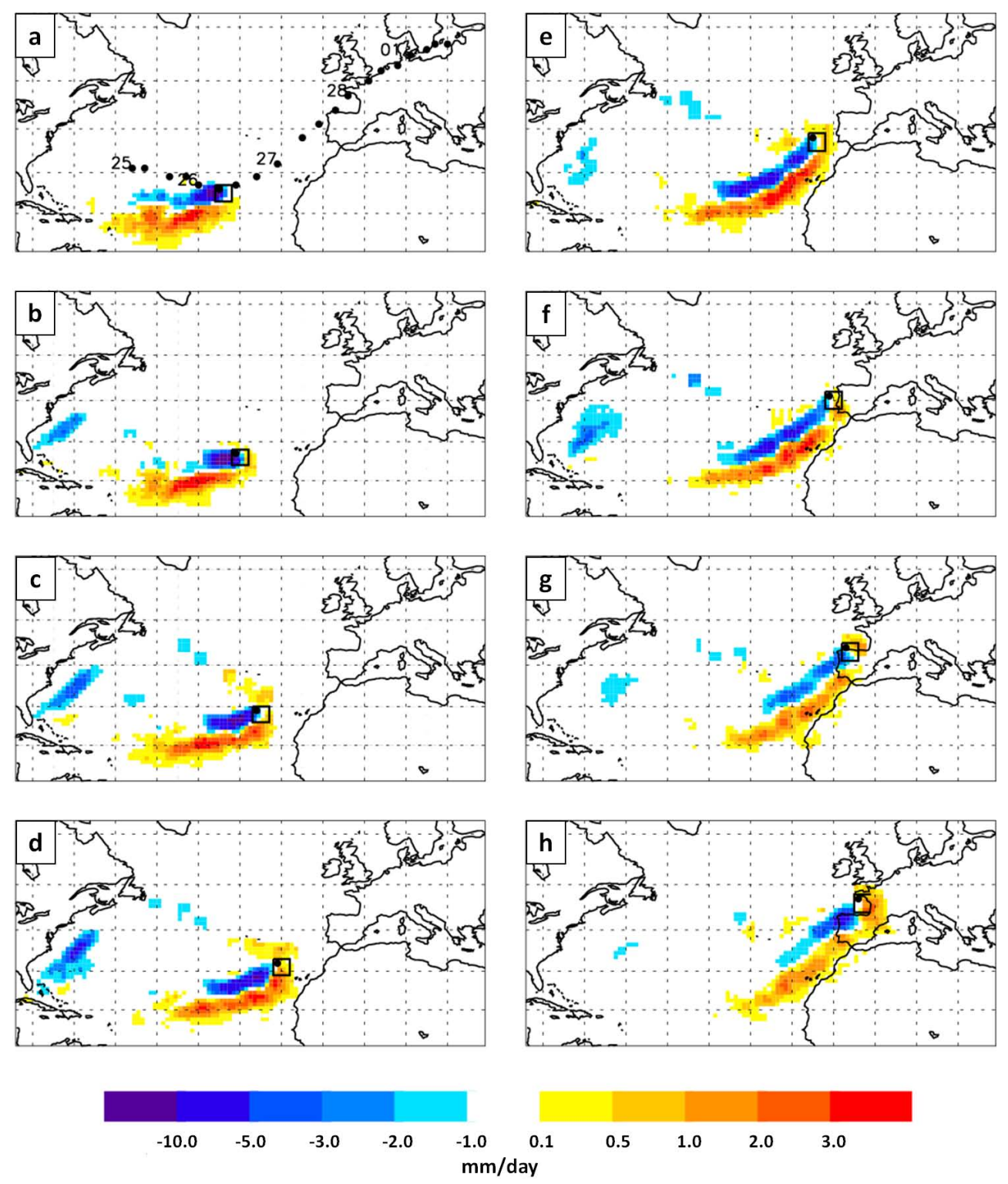

Fig. 8. Values of $(E-P)^{-2}\left(\mathrm{~mm} \mathrm{day}^{-1}\right)$ diagnosed from 10-day back trajectories of the target particles arriving in the box of $5^{\circ}$ latitude/longitude SE of the cyclone position as detected by the tracking scheme during explosive development, for (a) 06:00 UTC 26 February 2010; (b) 12:00 UTC 26 February 2010; (c) 18:00 UTC 26 February 2010; (d) 00:00 UTC 27 February 2010; (e) 06:00 UTC 27 February 2010; (f) 12:00 UTC 27 February 2010; (g) 18:00 UTC 27 February 2010; (h) 00:00 UTC 28 February 2010. The position of the storm at six-hourly intervals is marked with a filled circle on the first panel.

processes. The cold front and frontogenesis are well developed as shown on Fig. 5d. In other words, low latitudes baroclinic processes need intense tongue of moisture and temperature to supply additional energy in explosive cases. The assessment that the enhanced SST and moisture advection were instrumental for the development of storm Xynthia was recently confirmed by modelling sensitivity studies which considered reduced SST and modified latent heat fluxes (Ludwig et al., 2013).

These results agree with other recent works which have shown the key contribution from latent heat release to cy- clone intensification of explosive extratropical cyclones over the Atlantic Ocean, which are often accompanied by extreme values of $\theta_{\mathrm{e}}$ at $850 \mathrm{hPa}$ at their equatorward flank. This result is in line with Fink et al. (2012), which provided evidence that the baroclinic processes were less important than the diabatic ones during the deepening of the cyclone, since the latter processes contribute more to the observed surface pressure fall than horizontal temperature advection during the explosive deepening phase. 

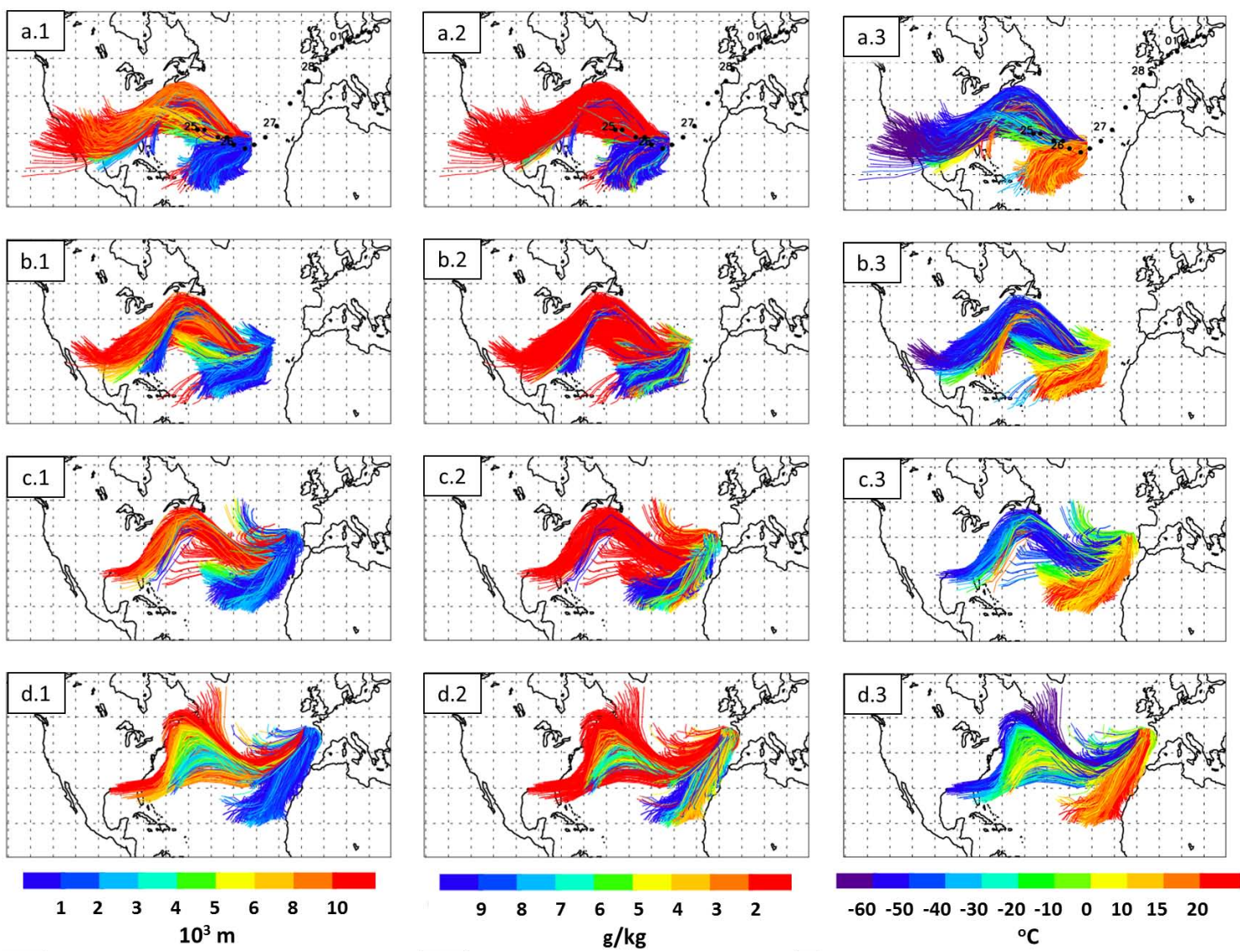

Fig. 9. Two days trajectories diagnosed from back trajectories of the target particles arriving in the box of $5^{\circ}$ latitude/longitude SE of the cyclone position as detected by the tracking scheme during explosive development. (a) for 06:00 UTC 26 February 2010; (b) for 18:00 UTC 26 February 2010; (c) for 06:00 UTC 27 February 2010; (d) for 18:00 UTC 27 February 2010. For each panel: (1) Height (m); (2) specific humidity $\left(\mathrm{g} \mathrm{kg}^{-1}\right)$; (3) temperature $\left({ }^{\circ} \mathrm{C}\right)$. The position of the storm at six-hourly intervals is marked with a filled circle on the top panels.

\section{Discussion and concluding remarks}

In the recent winter of 2009-2010 the south-western European sector was hit by destructive storms. The most important event was storm Xynthia, which underwent explosive deepening on 27 February over the Eastern NA and brought considerable damage to parts of south-western Europe including parts of France and even, at a lower degree, to Belgium, the Netherlands and Germany. Such exceptionally extreme cyclones are not so frequent at such comparatively southern latitudes (Trigo, 2006; Pinto et al., 2009; Liberato et al., 2011). Genesis, development and path of storm Xynthia were very uncommon. In this paper, a comprehensive assessment of the main impacts, the synoptic evolution and the dynamical mechanisms that forced the explosive development of storm Xynthia (26-28 February 2010) was presented. Focus was given to the key role played by the advection of warm, moist air masses on the explosive development. The evaporative oceanic sources were located over a large region of the subtropical NA Ocean, with a significant contribution from the tropics.
The attribution of mechanisms involved on this unusual explosive development allows us to confirm previous works that suggested that baroclinic processes are less important than the diabatic ones to the explosive deepening of these more southern, extreme extratropical cyclones (e.g. Liberato et al., 2011; Fink et al., 2012). In particular, we confirm that moisture advection from the subtropics and latent heat release during the development stages may play a very important role for cyclones undergoing explosive development at the southern edge of the NA storm track (c.f. also Liberato et al., 2011; Fink et al., 2012 for other examples). In particular, the export of low level tropical and subtropical moist air was associated with a significant positive anomaly of the SST over the subtropical NA sector (Fig. 4) was found to be determinant (see also Knipperz and Wernli, 2010). This region is a well-known oceanic source of Iberian precipitation (Gimeno et al., 2010) and as such it is natural to be involved in the occurrence of any extreme wet (dry) winters with warmer (colder) than usual conditions.

We consider these results to be particularly relevant within the context of the future warming of the global ocean that 
may alter the supply of moisture towards mid-latitude continental areas either by changes in the source characteristics or by indirect changes in large scale circulation (Gimeno et al., 2012). Even though Xynthia may be considered an unusual case under current climate conditions, it provides evidence that an enhanced SST and enhanced latent heat release may have a determinant impact for cyclone development. Recent studies suggest that the total number of extratropical cyclones may decrease on this region, but the intensity of extreme cyclones may increase (Ulbrich et al., 2009; Zappa et al., 2013). Among the factors contributing to the development of extreme cyclones, Pinto et al. (2009) suggested that the increase in $\theta_{\mathrm{e}}$ near the cyclone core may potentially be the most important change in a future climate. This is particularly true for cyclones developing on the southern edge of the NA storm track, which may be then more strongly diabatically driven than under present climate conditions.

Research on extreme cases occurring on western Iberia region and associated dynamical processes and variability are of utmost importance, namely to better understand the occurrence of such extreme events. Future work will focus on earlier cases like the windstorm and storm surge in 1724 (e.g. Domínguez-Castro et al., 2012) through the analysis of relevant historical data, thus contributing to put these storms into a long-term climatic perspective.

\section{Supplementary material related to this article is available online at: \\ http://www.nat-hazards-earth-syst-sci.net/13/2239/2013/ nhess-13-2239-2013-supplement.zip.}

\section{References}

Andrade, C., Santos, J. A., Pinto, J. G., and Corte-Real, J.: Largescale atmospheric dynamics of the wet winter 2009-2010 and its impact on hydrology in Portugal, Clim. Res., 46, 29-41, 2011.

Aon Benfield: Annual Global Climate and Catastrophe Report Impact Forecasting - 2010, 2010, available at: http://www.aon.com, last access: 9 December, 2012.

Bergeron, T.: Reviews of modern meteorology-12: The problem of tropical hurricanes, Q. J. Roy. Meteor. Soc., 80, 131-164, 1954.

Bolton, D.: The Computation of Equivalent Potential Temperature, Mon. Weather Rev., 108, 1046-1053, 1980.

Born, K., Ludwig, P., and Pinto, J. G.: Wind gust estimation for Mid-European winter storms: towards a probabilistic view, Tellus A, 64, 17471, doi:10.3402/tellusa.v64i0.17471, 2012.

Browning, K. A.: The dry intrusion perspective of extra-tropical cyclone development, Met. Apps, 4, 317-324, 1997.

Cattiaux, J., Vautard, R., Cassou, C., Yiou, P., Masson-Delmotte, V., and Codron, F., Winter 2010 in Europe: A cold extreme in a warming climate, Geophys. Res. Lett. 37, L20704, doi:10.1029/2010GL044613, 2010.

Chang, C. B., Pepkey, D. J., and Kreitzberg, C. W.: Latent heat induced energy transformations during cyclogenesis, Mon. Weather Rev., 112, 357-367, 1984.

Dacre, H. F., Hawcroft M. K., Stringer M. A., and Hodges K. I.: An Extratropical Cyclone Atlas: A Tool for Illustrating Cyclone Structure and Evolution Characteristics, B. Am. Meteorol. Soc., 93, 1497-1502, 2012.

Dee, D. P., Uppala, S. M., Simmons, A. J., Berrisford, P., Poli, P., Kobayashi, S., Andrae, U., Balmaseda, M. A., Balsamo, G., Bauer, P., Bechtold, P., Beljaars, A. C. M., van de Berg, L., Bidlot, J., Bormann, N., Delsol, C., Dragani, R., Fuentes, M., Geer, A. J., Haimberger, L., Healy, S. B., Hersbach, H., Hólm, E. V., Isaksen, L., Kållberg, P., Köhler, M., Matricardi, M., McNally, A. P., Monge-Sanz, B. M., Morcrette, J.-J., Park, B.-K., Peubey, C., de Rosnay, P., Tavolato, C., Thépaut, J.-N. and Vitart, F.: The ERA-Interim reanalysis: configuration and performance of the data assimilation system, Q. J. R. Meteorol. Soc., 137, 553-597, doi:10.1002/qj.828, 2011.

Domínguez-Castro, F., Trigo, R. M., and Vaquero, J. M.: The first meteorological measurements in the Iberian Peninsula: evaluating the storm of November 1724, Clim. Change, 118, 443-455, doi:10.1007/s10584-012-0628-9, 2013.

Enfield, D. B. and Mayer, D. A.: Tropical Atlantic SST variability and its relation to El Niño-Southern Oscillation, J. Geophys. Res., 102, 929-945, 1997.

Fink, A. H., Brücher, T., Ermert, V., Krüger, A., and Pinto, J. G.: The European storm Kyrill in January 2007: synoptic evolution, meteorological impacts and some considerations with respect to climate change, Nat. Hazards Earth Syst. Sci., 9, 405-423, doi:10.5194/nhess-9-405-2009, 2009.

Fink A. H, Pohle, S., and Pinto, J. G., and Knippertz, P.: Diagnosing the influence of diabatic processes on the explosive deepening of extratropical cyclones over the North Atlantic, Geophys. Res. Lett., 39, L07803, doi:10.1029/2012GL051025, 2012.

Fragoso, M., Trigo, R. M., Pinto, J. G., Lopes, S., Lopes, A., U1brich, S., and Magro, C.: The 20 February 2010 Madeira flashfloods: synoptic analysis and extreme rainfall assessment, Nat. Hazards Earth Syst. Sci., 12, 715-730, doi:10.5194/nhess-12715-2012, 2012. 
Gimeno, L., Nieto, R., Trigo, R. M., Vicente-Serrano, S., and Lopez-Moreno, J. I.: Where does the Iberian Peninsula moisture come from? An answer based on a Largrangian approach, J. Hydrometeorol., 11, 421-436, 2010.

Gimeno, L., Stohl, A., Trigo, R. M., Dominguez, F., Yoshimira, K., Yu, L., Drumond, A., Durán-Quesada, A. M., and Nieto, R.: Oceanic and Terrestrial Sources of Continental Precipitation, Rev. Geophys., 50, RG4003, doi:10.1029/2012RG000389, 2012.

Knippertz, P. and Wernli, H.: A Lagrangian Climatology of Tropical Moisture Exports to the Northern Hemispheric Extratropics, J. Climate, 23, 987-1003, 2010.

Lamb, H. H.: Historic storms of the North Sea, British Isles, and Northwest Europe, Cambridge University Press, Cambridge, 204 pp., 1991.

Liberato, M. R. L., Pinto, J. G., Trigo, I. F., and Trigo R. M.: Klaus - an exceptional winter storm over Northern Iberia and Southern France, Weather, 66, 330-334, 2011.

Liberato, M. L. R., Ramos, A. M., Trigo, R. M., Trigo, I. F., Durán-Quesada, A. M., Nieto, R., and Gimeno, L.: Moisture Sources and Large-Scale Dynamics Associated With a Flash Flood Event, in: Lagrangian Modeling of the Atmosphere, edited by: Lin, J., Brunner, D., Gerbig, C., Stohl, A., Luhar, A., and Webley, P., American Geophysical Union, Washington, DC, http://onlinelibrary.wiley.com/doi/10. 1029/2012GM001244/summary, 2012.

Ludwig, P., Pinto, J. G., Reyers, M., and Gray, S. L.: The role of anomalous SST and surface fluxes over the Southeastern North Atlantic in the explosive development of windstorm Xynthia, Q. J. R. Meteor. Soc., revised, 2013.

Lumbroso, D. M. and Vinet, F.: A comparison of the causes, effects and aftermaths of the coastal flooding of England in 1953 and France in 2010, Nat. Hazards Earth Syst. Sci., 11, 2321-2333, doi:10.5194/nhess-11-2321-2011, 2011.

Pinto, J. G., Zacharias, S., Fink, A. H., Leckebusch, G. C., and Ulbrich, U.: Factors contributing to the development of extreme North Atlantic cyclones and their relationship with the NAO, Clim. Dynam., 32, 711-737, 2009.

Rockel, B., Will, A., and Hense, A.: Special Issue: Regional climate modelling with COSMO-CLM (CCLM), Meteorol. Z., 17, 347348, 2008.

Sanders, F. and Gyakum, J. R.: Synoptic-dynamic climatology of the "bomb", Mon. Weather Rev., 108, 1589-1606, 1980.

Santos, J. A., Woollings, T., and Pinto, J. G.: Are the winters 2010 and 2012 archetypes exhibiting extreme opposite behavior of the North Atlantic jet stream?, Mon. Weather Rev., doi:10.1175/MWR-D-13-00024.1, 2013.

Seager, R., Kushnir, Y., Nakamura, J., Ting, M., and Naik, N.: Northern Hemisphere winter snow anomalies: ENSO, NAO and the winter of 2009/10, Geophys. Res. Lett., 37, L14703, doi:10.1029/2010GL043830, 2010.
Stohl, A., Hittenberger, M., and Wotawa, G.: Validation of the Lagrangian particle dispersion model FLEXPART against large scale tracer experiment data, Atmos. Environ., 32, 4245-4264, 1998.

Stohl, A. and James, P.: A Lagrangian analysis of the atmospheric branch of the global water cycle. Part 1: Method description, validation, and demonstration for the August 2002 flooding in central Europe, J. Hydrometeorol., 5, 656-678, 2004.

Stohl, A. and James, P.: A Lagrangian analysis of the atmospheric branch of the global water cycle. Part 2: Earth's river catchments, ocean basins, and moisture transports between them, J. Hydrometeorol., 6, 961-984, 2005.

Stohl, A., Forster, C., Frank, A., Seibert, P., and Wotawa, G.: Technical note: The Lagrangian particle dispersion model FLEXPART version 6.2, Atmos. Chem. Phys., 5, 2461-2474, doi:10.5194/acp-5-2461-2005, 2005.

Trigo, I. F.: Climatology and Interannual Variability of StormTracks in the Euro-Atlantic sector: a comparison between ERA40 and NCEP/NCAR Reanalyses. Clim. Dynam., 26, 127-143, 2006.

Uccellini, L. W. and Johnson, D. R.: The coupling of upper and lower tropospheric jet streaks and implications for the development of severe convective storms, Mon. Weather Rev., 107, 682703, 1979.

Ulbrich, U., Leckebusch, G. C., and Pinto J. G.: Extra-tropical cyclones in the present and future climate: a review, Theor. Appl. Climatol., 96, 117-131, 2009.

Vicente-Serrano, S. M, Trigo, R. M, López-Moreno, J. I, Liberato, M. L. R, Lorenzo-Lacruz, J., Beguería, S., Morán-Tejeda, E., and El Kenawy, A.: Extreme winter precipitation in the Iberian Peninsula in 2010: anomalies, driving mechanisms and future projections, Clim. Res., 46, 51-65, 2011.

Wang, C., Liu, H., and Lee, S.: The record-breaking cold temperatures during the winter of 2009/2010 in the Northern Hemisphere, Atmos. Sci. Lett., 11, 161-168, 2010.

Wanner, H., Bronnimann, S., Casty, C., Gyalistras, D., Luterbacher, J., Schmutz, C., Stephenson, D. B., and Xoplaki, E.: North Atlantic Oscillation-concepts and studies, Surv. Geophys., 22, 321382, 2001.

Zappa, G., Shaffrey, L. C., Hodges, K. I., Sansom, P. G., and Stephenson, D. B.: A multi-model assessment of future projections of North Atlantic and European extratropical cyclones in the CMIP5 climate models, J. Climate, 26, 5846-5862, 2013. 